\title{
Multidisciplinary approach to connective tissue disease (CTD) related pleural effusions: a four-year retrospective evaluation
}

Hugh Ip ${ }^{*}$ (D), Parthipan Sivakumar, Eugene Ace McDermott, Sangita Agarwal, Boris Lams, Alex West and Liju Ahmed

\begin{abstract}
Background: CTD-related pleural effusions are rare and challenging to diagnose. Our lung inflammation service (with expertise in rheumatology, interstitial lung disease and respiratory failure) works closely with the pleural team. This study aims to review the multidisciplinary approach to CTD-related pleural effusions at a tertiary centre.

Methods: All patients with CTD-related pleural effusions at St Thomas' Hospital, London were included. Retrospective data were collected from Dec 2013 to 2016.

Results: The lung inflammation service performed an expert clinical assessment and targeted investigations. 11 patients (ages 23-77) were identified with CTD related pleural disease. 9 (82\%) patients were given a new CTD diagnosis, with pleural disease as the first manifestation. The range of conditions were: rheumatoid arthritis [3], IgG4-related disease [2] ,adult Still's disease [2] ,vasculitis [1] ,SLE [1], drug-induced lupus [1], and Behcet's [1].

The pleural team review took place 1 day (median) after referral. $73 \%$ of diagnoses (8 patients) were achieved with local anaesthetic pleural interventions (a combination of: aspiration, drain, or percutaneous biopsy). This included 1 patient who required no pleural intervention. 1 required medical thoracoscopy, and 2 underwent thoracic surgery.

Diagnoses were made by integrating all available evidence such as clinical assessment, imaging, and autoimmune serology. No diagnosis was achieved by pleural cytology or histology analysis alone.

8 (73\%) were commenced on prednisolone acutely (vasculitis, SLE, drug-related lupus, 1 patient with rheumatoid arthritis, Behcet's, 2 patients with Adult Still's disease, 1 patient with IgG4-related disease). Of these 8, one patient with rheumatoid arthritis received IV methylprednisolone beforehand, one patient with lgG4-related disease was weaned off prednisolone to methothrexate, two patients with Adult Still's disease were on colchicine as well, and one patient with Behcet's was on cyclophosphamide as well. 7 (64\%) were managed as outpatients; 4 required admission. The median time from pleural review to diagnosis was 53 days.
\end{abstract}

Conclusions: Diagnosis can be challenging in patients presenting with pleural disease as the first manifestation of a CTD. We recommend a multidisciplinary approach in management.

Keywords: Pleural effusion, Pleura, Thoracoscopy, Connective tissue disease

\footnotetext{
* Correspondence: hughip@gmail.com

Guy's and St Thomas' NHS Foundation Trust, Westminster Bridge Road,

London SE1 7EH, UK
}

(c) The Author(s). 2019 Open Access This article is distributed under the terms of the Creative Commons Attribution 4.0 International License (http://creativecommons.org/licenses/by/4.0/), which permits unrestricted use, distribution, and reproduction in any medium, provided you give appropriate credit to the original author(s) and the source, provide a link to the Creative Commons license, and indicate if changes were made. The Creative Commons Public Domain Dedication waiver (http://creativecommons.org/publicdomain/zero/1.0/) applies to the data made available in this article, unless otherwise stated. 


\section{Background}

A new pleural effusion may be caused by a wide range of conditions. The British Thoracic Society produced guidelines in 2010 recommending a systematic approach to achieve a diagnosis, aiming to streamline investigations and interventions [1]. Since then, the evidence base for managing malignant and infective effusions has developed through a series of clinical trials. In comparison, research on benign non-infective pleural effusions has been more limited [2]. A number of these are caused by connective tissue diseases (CTD).

Pleural effusions from CTD are caused by increased capillary permeability, as extravascular fluid moves from the lung's interstitium, across the mesothelium into the pleural space [3]. This may be due to a number of reasons [4], such as a pleural infiltrative process. In addition, circulating immune complexes that localise to the pleura, can activate the complement system causing endothelial injury. Enzyme and free radical release from white blood cells also accentuate the inflammatory process.

CTD-related pleural effusions are rare and challenging to diagnose. The most common CTDs to affect the pleura are rheumatoid arthritis and systemic lupus erythematosus (SLE) [1]. A prospective observational cohort study over 7 years at a specialist pleural unit identified 356 nonmalignant pleural effusions. 9.8\% of these were given a diagnosis of inflammatory pleuritis, and $7.6 \%$ attributed to other diagnoses (including chylothorax, rheumatic causes, trauma, and drug-induced causes) [5].

The same unit described the value of a pleural specialist team to improve the efficacy and efficiency of managing patients with pleural disease [6]. In most pleural teams, the medical specialties involved are commonly: respiratory, oncology and palliative care. However, the pleural team in our centre works closely with the lung inflammation service, with expertise in rheumatology, interstitial lung disease and respiratory failure. This study aims to review the multidisciplinary approach to CTD-related pleural effusions at a tertiary centre. To our knowledge, there is no published evidence describing a multidisciplinary approach to CTD-related pleural effusions.

\section{Methods}

\section{Study design}

This study is a retrospective evaluation of cases. We reviewed electronic hospital records, imaging, blood tests, pleural fluid analysis and pleural biopsy analysis. Data were collected relating to CTD diagnosis, pleural and surgical interventions, and CTD specific systemic therapy.

As a retrospective service evaluation, written patient informed consent and regional ethics approval was not required.
Table 1 Patient demographics

\begin{tabular}{ll}
\hline Characteristic & $n(\%)$ \\
\hline Gender $(n=11)$ & $8(73)$ \\
Male & $3(27)$ \\
Female & $23-77$ \\
Age range & 50 \\
Median age & \\
CTD diagnosis & $3(27)$ \\
Rheumatoid arthritis & $2(18)$ \\
IgG4-related disease & $2(18)$ \\
Adult Still's disease & $1(9)$ \\
Vasculitis & $1(9)$ \\
SLE & $1(9)$ \\
Drug-induced lupus & $1(9)$ \\
Behcet's &
\end{tabular}

\section{Participants}

All patients diagnosed with CTD-related pleural effusions at St Thomas' Hospital, London were included. We included patients referred to pleural clinic between November 2012 and 2016. These patients are usually referred by the general medical or rheumatology teams for a specialist pleural opinion when the etiology of the pleural effusion is unclear, or where there is an acute clinical concern. We excluded patients with a CTD attending pleural clinic with a pleural effusion due to other (non-CTD related) etiologies.

\section{Interventions}

Pleural aspirations, drains, biopsies and medical thoracoscopies were performed in the pleural clinic at St Thomas' Hospital in accordance with national guidelines $[7,8]$. Out of hours, aspirations and drains were performed by the radiology department.

\section{Assessments}

Statistical analysis was carried out using Microsoft Excel. Descriptive statistics were used to evaluable the service,

Table 2 Pleural/surgical interventions

\begin{tabular}{ll}
\hline Pleural intervention & $n(\%)$ \\
\hline None & $1(9)$ \\
Pleural aspiration only & $3(27)$ \\
Chest drain only & $2(18)$ \\
Pleural aspiration and chest drain & $1(9)$ \\
Pleural aspiration and biopsy & $1(9)$ \\
Pleural aspiration and biopsy, drain and VATS & $1(9)$ \\
Pleural aspiration and medical thoracoscopy & $1(9)$ \\
VATS, thoracotomy, pericardiectomy & $1(9)$ \\
\hline
\end{tabular}




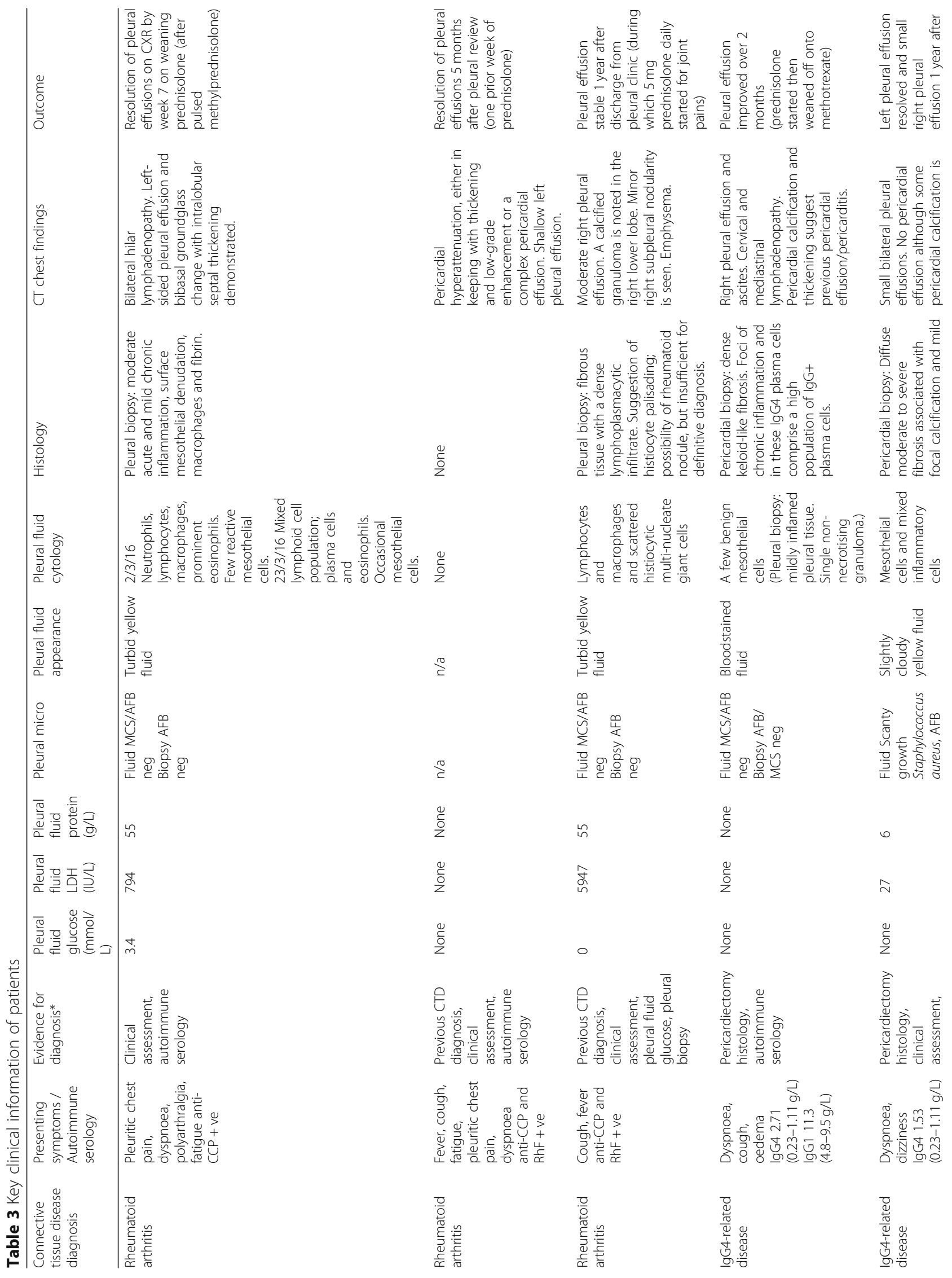




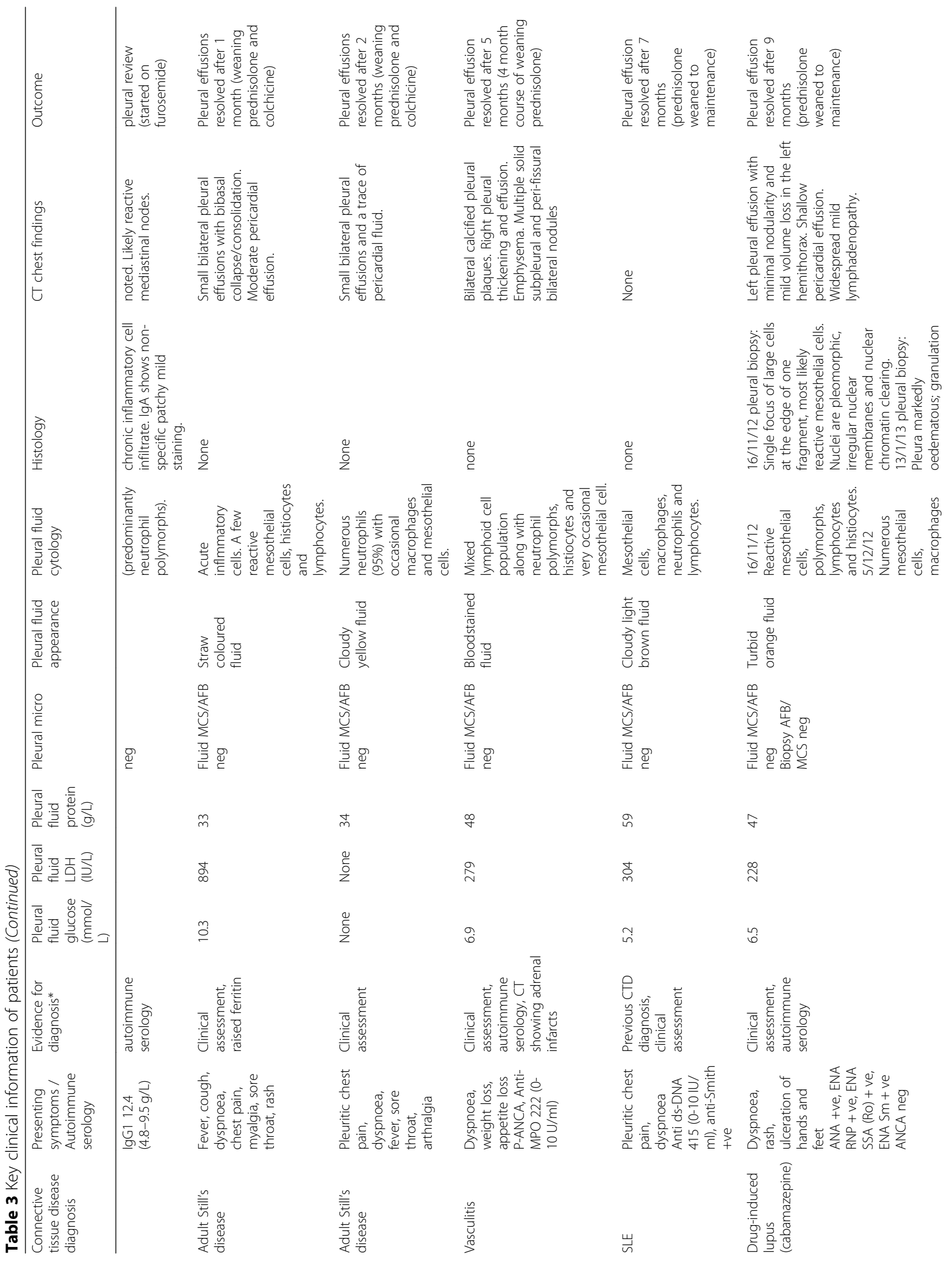




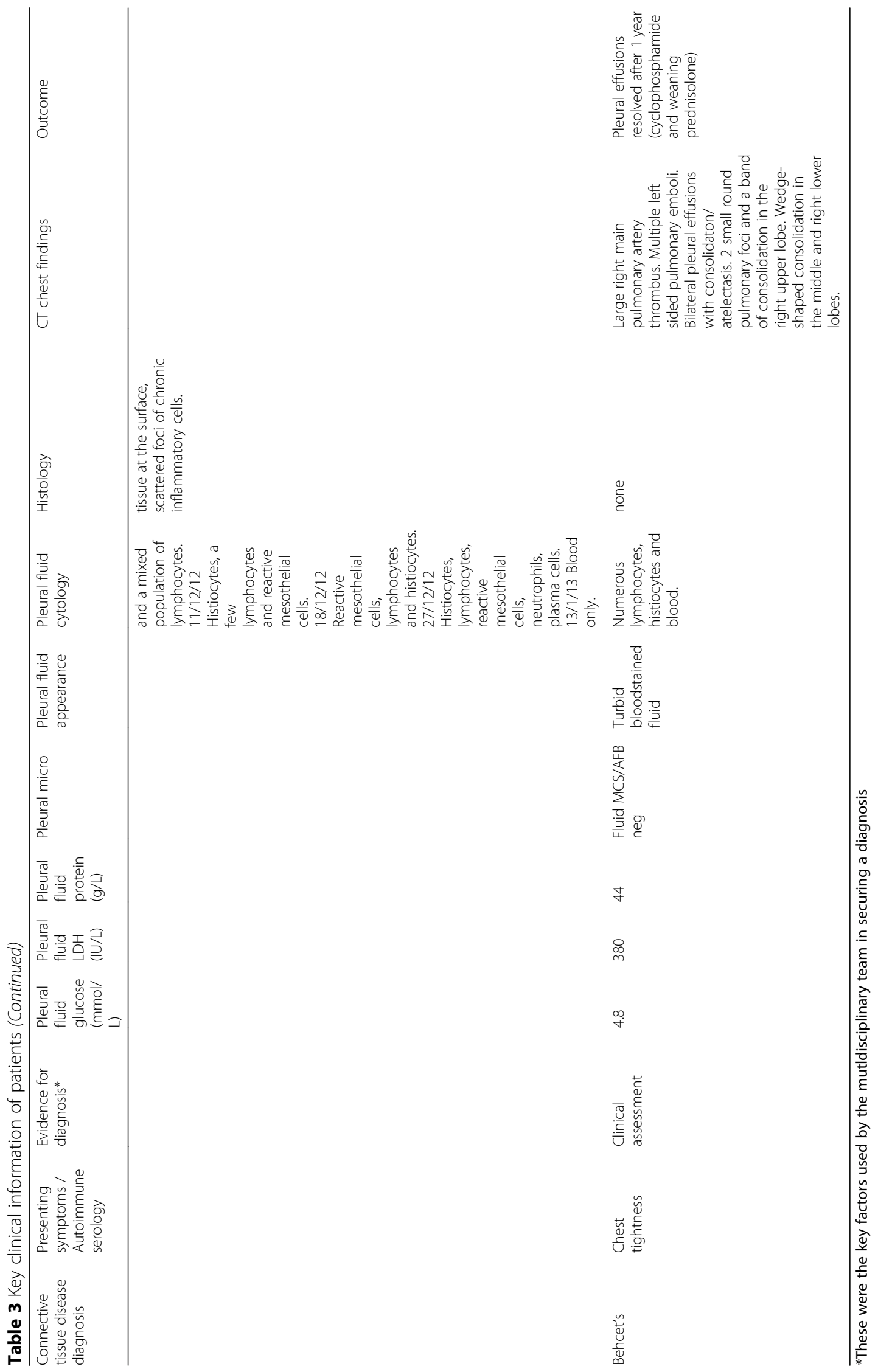


and to summarise the clinical characteristics of the subjects.

\section{Results}

Eleven patients (ages 23-77) were identified with CTD related pleural disease (Table 1). They were seen by the lung inflammation service, who performed an expert clinical assessment and targeted investigations, usually after review by the pleural team. $9(82 \%)$ patients were given a new CTD diagnosis, with pleural disease as the first manifestation. The range of conditions were: rheumatoid arthritis [3], IgG4-related disease [2], adult Still's disease [2], vasculitis [1], SLE [1], drug (carbamazepine)-induced lupus [1], and Behcet's [1].

The pleural team review took place 1 day (median) after referral. $73 \%$ of diagnoses (8 patients) were achieved with local anaesthetic pleural interventions (a combination of: aspiration, drain, or percutaneous biopsy). This included 1 patient who required no pleural intervention. 1 required medical thoracoscopy, and 2 underwent thoracic surgery (Table 2). The patient who underwent a medical thoracoscopy (for pleural thickening) after an aspiration, had a final diagnosis of a rheumatoid arthritis associated pleural effusion. One patient who underwent thoracic surgery was referred directly to the surgical team, subsequently requiring a pericardiectomy for a diagnosis of IgG4-related disease. Another patient underwent VATS to rule out a pleural malignancy, before commencing treatment for a pleural effusion related to drug-induced lupus.

Table 3 illustrates how diagnoses were made by integrating and analysing all available evidence, to include clinical assessment, imaging, and autoimmune serology. No diagnosis was achieved by pleural cytology or histology analysis alone. The pleural fluid $\mathrm{pH}$ was not measured for these patients (although it is available at our centre), as pleural infection was low on the list of differentials.

Eight (73\%) were commenced on prednisolone acutely (vasculitis, SLE, drug-related lupus, 1 patient with rheumatoid arthritis, Behcet's, 2 patients with Adult Still's disease, 1 patient with IgG4-related disease). Of these 8 , one patient with rheumatoid arthritis received IV methylprednisolone beforehand, one patient with IgG4-related disease was weaned off prednisolone to methothrexate, two patients with Adult Still's disease were on colchicine as well, and one patient with Behcet's was on cyclophosphamide as well. 7 (64\%) were managed as outpatients; 4 required admission. The median time from pleural review to diagnosis was 53 days.

\section{Discussion}

In the work up for interstitial lung disease (ILD), assessment by a rheumatologist is recommended in suspected CTD [9]. The input of a rheumatologist is invaluable in providing an expert clinical review, then directing and interpreting autoimmune testing. Our centre has found this to be the case - in managing CTD-related pleural effusions. The lung inflammation service was set up to assist the critical critical care team in managing severe respiratory failure; they now work closely with the pleural service as well. To our knowledge, this is the first published evaluation of a collborative approach for inflammatory pleural disease. Case reports of CTD-related serositis do not describe a similarly coordinated approach [10-12]. Our results suggest that the value of pleural fluid and tissue analysis is to exclude common conditions such as malignancy and infection, while a multidisciplinary approach integrating all available diagnostic information is needed for complex cases such as CTD related pleuritis.

In this service evaluation, the multidisciplinary approach to CTD-related pleural effusions has demonstrated efficiency in achieving a diagnosis in a median of 53 days from the first review by the pleural team. Pleural procedures were streamlined, with $73 \%$ of diagnoses being achieved by local anaesthetic interventions. $64 \%$ of cases were managed in the outpatient setting. Published data describe the outcomes of pleural service outcomes as a whole $[13,14]$. This is the first study to focus on the management of CTD-related pleural effusions.

The study was limited by the small number of cases, due to the rareity of CTD-related pleural effusions. A multi-centre collaboration to establish a larger database would facilitate advancement in best managing this complex patient cohort.

\section{Conclusions}

Diagnosis can be challenging in patients presenting with pleural disease as the first manifestation of a CTD. We recommend a multidisciplinary approach in management.

\section{Abbreviations}

CTD: connective disease disease; ILD: interstitial lung disease; SLE: systemic lupus erythematosus; VATS: video-assisted thoracoscopic surgery

\section{Acknowledgements}

We would like to thank all the patients involved in this study. We are also indebted to the pleural team of doctors and nurses for facilitating each patient's journey in clinic.

\section{Authors' contributions \\ $\mathrm{HI}$ contributed to study design, data collection, statistical analysis, data interpretation, clinical care and wrote the first draft of the manuscript. PS contributed to study design, data collection, statistical analysis, data interpretation, clinical care and manuscript drafting. EAM participated in data collection and manuscript drafting. SA, BL and AW contributed to data interpretation, clinical care and manuscript drafting. LA conceived the study and contributed to clinical care, statistical analysis, data interpretation and manuscript drafting. All authors read and approved the final manuscript.}

Authors' information

$\mathrm{HI}$ is a respiratory registrar, and clinical research fellow in pleural disease. $\mathrm{PS}$ is a respiratory registrar, post-graduate MD student and trial coordinator of the OPTIMUM trial.

EAM is a medical student. 
SA is a rheumatology consultant.

$\mathrm{BL}$ is a respiratory consultant with specialist interests in interstitial lung disease and respiratory failure.

AW is a respiratory consultant with specialist interests in pleural disease and interstitial lung disease.

$L A$ is a respiratory consultant with specialist interest in pleural disease, Senior Honorary Lecturer at KCL, and the Chief Investigator for OPTIMUM trial. LA has secured funding from Becton and Dikinson Ltd. for the OPTIMUM trial.

\section{Funding}

Open access for this article was funded by King's College London.

\section{Availability of data and materials}

Due to our local governance policy, we do not have permission to make the data sets on which the conclusions of the paper rely publicly available. A truncated data set (removing all potentially identifying features) may be made available on an individual request basis.

\section{Ethics approval and consent to participate}

As a retrospective service evaluation, written patient informed consent and regional ethics approval was not required.

\section{Consent for publication}

Not applicable.

\section{Competing interests}

The authors declare that they have no competing interests.

Received: 4 July 2018 Accepted: 14 August 2019

Published online: 27 August 2019

\section{References}

1. Hooper C, Lee YCG, et al. British Thoracic Society pleural disease guideline 2010. Thorax. 2010;65(Suppl 2):ii4-ii17.

2. Bintcliffe OJ, Lee YCG, et al. The management of benign non-infective pleural effusions. Eur Respir Rev. 2016;25:303-16.

3. Ferreiro L, Álvarez-Dobaño JM, Valdés L. Systemic diseases and the pleura. Arch Bronconeumol. 2011:47(7):361-70.

4. Joseph J, Sahn SA. Connective tissue diseases and the pleura. Chest. 1993; 104:262-70.

5. Walker SP, Morley AJ, et al. Nonmalignant Pleural Effusions. Chest. 2017; 151(5):1099-105.

6. Bhatnagar R, Maskell N. Developing a 'pleural team' to run a reactive pleural service. Clin Med. 2013;13(5):452-6.

7. Rahman NM, Ali NJ, et al. British Thoracic Society pleural disease guideline 2010. Thorax. 2010;65(Suppl 2):ii54-60

8. Havelock T, Teoh R, et al. British Thoracic Society pleural disease guideline 2010. Thorax. 2010;65(Suppl 2):ii61-76.

9. Prasad JD, Mahar A, et al. The interstitial lung disease multidisciplinary meeting: a position statement from the Thoracic Society of Australia and new Zealand and the Lung Foundation Australia. Respirology. 2017 Oct; 22(7):1459-72.

10. Akagi T, Mukai T, Kodama S, et al. POEMS syndrome in a patient with rheumatoid arthritis.Case Rep. 2017;2017:bcr-2017-220875.

11. Szeto MCH, Disney B, Perkins $P$, et al. Ascites and other incidental findings revealing undiagnosed systemic rheumatoid arthritis. Case Rep. 2015;2015 bcr2014207142.

12. Malone C, McCarthy G. Polymyalgia Rheumatica as an unusual cause of pleural and pericardial effusion. J Clin Rheumatol. 2005:11:59-60.

13. Fawzi A, Maddekar N, Khan S, et al. M20 Pleural service in a large university teaching hospital - 1 year retrospective review. Thorax. 2016;71:A268.

14. Brockelsby $C$, Wells $A$, Deegan $P$, et al. P13 the rationale for setting up a dedicated pleural procedure list: benefits for patients and trusts. Thorax. 2016;71:A90.

\section{Publisher's Note}

Springer Nature remains neutral with regard to jurisdictional claims in published maps and institutional affiliations.

Ready to submit your research? Choose BMC and benefit from:

- fast, convenient online submission

- thorough peer review by experienced researchers in your field

- rapid publication on acceptance

- support for research data, including large and complex data types

- gold Open Access which fosters wider collaboration and increased citations

- maximum visibility for your research: over $100 \mathrm{M}$ website views per year

At BMC, research is always in progress.

Learn more biomedcentral.com/submissions 